\title{
EFFECTS OF SEASON AND POSTMORTEM CHANGES ON BLOOD ANALYTES IN PYRENEAN CHAMOIS (RUPICAPRA PYRENAICA PYRENAICA)
}

\author{
Asta Tvarijonaviciute, ${ }^{1}$ Ignasi Marco, ${ }^{1}$ Rafaela Cuenca, ${ }^{1}$ Santiago Lavín, ${ }^{1}$ and Josep Pastor ${ }^{1,2}$ \\ ${ }^{1}$ Serveid'Ecopatologia de Fauna Salvatge, Departament de Medicina i Cirurgia Animals, Universitat Autònoma de \\ Barcelona, 08193 Bellaterra, Spain \\ ${ }^{2}$ Corresponding author (email: Josep.Pastor@uab.cat)
}

ABSTRACT: Our objectives were to evaluate the effects of the 1) season, and 2) postmortem changes on serum biochemistries related with metabolism in Pyrenean chamois (Rupicapra pyrenaica pyrenaica). Serum samples from 98 animals obtained from 2009 to 2012 were included. To investigate seasonal influences on blood parameters, the Pyrenean chamois were captured in drive-nets during the feed abundant $(\mathrm{FA} ; n=32)$ and food deficient $(\mathrm{FD} ; n=35)$ seasons. To evaluate the possible differences in biochemistry analytes when sampling live or dead animals, we used serum samples from 32 captured animals and 31 dead animals (obtained during controlled hunting) in the FA season. Significant increases in high-density lipoprotein cholesterol (24\%), nonesterified fatty acids (NEFA, 190\%), total antioxidant capacity $(68 \%)$, and haptoglobin $(33 \%)$ were observed in FD when compared with FA seasons. Albumin and insulin-like growth factor-1 (IGF-1) showed statistically significant decreases of $10 \%$ and $11 \%$, respectively, in samples taken in the FD season compared to the FA season. Statistically significant higher concentrations were found in serum low-density lipoprotein cholesterol $(22 \%)$, triglycerides (28\%), acetylcholinesterase (50\%), NEFA (383\%), albumin (18\%), IGF-1 (53\%), cortisol (959\%), and paraoxonase-1 (20\%) in samples collected from live animals compared to samples collected from dead ones. We demonstrated that season should be taken into account when evaluating serum biochemistries in Pyrenean chamois because, in the FD season, these animals present lipid mobilization, decreased albumin and IGF-1, and increased total antioxidant capacity compared with the FA season. In addition, if samples are taken from dead animals, observed decreases in serum lowdensity lipoprotein cholesterol, triglycerides, albumin, paraoxonase-1, acetylcholinesterase, NEFA, cortisol, IGF-1, and an increase in haptoglobin should be expected.

Key words: Blood, chamois, clinical pathology, lipid metabolism, Rupicapra pyrenaica pyrenaica, season, serum biochemistry.

\section{INTRODUCTION}

The Pyrenean chamois (Rupicapra pyrenaica pyrenaica; Family Bovidae; Subfamily Caprinae) is a small mountain ungulate that feeds predominantly on herbaceous plants and is widely distributed in alpine and subalpine habitats in the French and Spanish Pyrenees. This high-mountain ecosystem presents harsh and highly variable environment conditions. During the winter season, the absence of plant growth, low temperature, and snow cover significantly reduce the nutritional resources and influence the values of biologic parameters in the Pyrenean chamois (Gonzalez and Crampe 2001; Crampe et al. 2002). Furthermore, the rut season for chamois in November represents a period of higher energy output and a considerable decrease in food intake, resulting in reduced body weight, especially in males (Perez-Barberia et al. 1998; Weber 2004). However, no studies have been reported regarding seasonal influence on blood analytes related to lipid metabolism. The study of the possible seasonal influences on blood analytes related with lipid metabolism could help to understand how these animals respond to the changing conditions of different seasons, such as food availability.

Sampling of wild animals causes stress due to their capture, resulting in altered blood biochemistry and thus hindering correct evaluation of health or nutritional status (or both) of the animal (Gibert 1991). The possibility of obtaining samples from dead animals (i.e., from controlled hunting) could contribute to evaluating the health status of wild animals. Postmortem changes affecting 
blood analytes are well described in humans (Forrest 1993). Although some data have been reported for other wild animals, such as red deer (Cervus elaphus; Bateson and Bradshaw 1997), no such data have been reported from Pyrenean chamois.

We studied the effects of sampling during different seasons and the possible effects of postmortem changes on serum biochemistries related to metabolism in Pyrenean chamois. For this purpose, a metabolic profile was obtained from serum samples obtained from live animals in food abundant (FA) and food deficient (FD) season and from dead animals in FA season. The panel consisted of lipids and lipid metabolism-related markers such as total cholesterol, high-density lipoprotein cholesterol (HDL-C), low-density lipoprotein cholesterol (LDL-C), triglycerides (Tg), acetylcholinesterase (AChE), bile acids, nonesterified fatty acids (NEFA), and butyrate as well as markers related with nutrition such as albumin and insulin-like growth factor I (IGF1), a stress marker (cortisol), the acute phase protein haptoglobin ( $\mathrm{Hp})$, liver enzymes including alkaline phosphatase (ALP) and aspartate aminotransferase (AST), and the oxidative status markers, total antioxidant capacity (TAC), and paraoxonase-1 (PON1).

\section{MATERIALS AND METHODS}

\section{Study area}

The study area was in the Catalan Pyrenees $\left(42^{\circ} 13^{\prime}-42^{\circ} 50^{\prime} \mathrm{N}, 0^{\circ} 39^{\prime}-2^{\circ} 20^{\prime} \mathrm{E}\right)$, with the lower parts at $800-900 \mathrm{~m}$ elevation and the highest peaks at 3,143 $\mathrm{m}$ of elevation. The mean annual rainfall ranged from 850 to $1,500 \mathrm{~mm}$. Chamois inhabit mountain forests $(800-1,600 \mathrm{~m}$ of elevation), subalpine forests $(1,700-2,200 \mathrm{~m}$ of elevation), and alpine pastures $(>2,300 \mathrm{~m}$ of elevation), areas of approximately 175,000 ha.

\section{Animals}

The description of the animals included in this investigation is presented in the Table 1 . Animals were sampled between 2009 and 2012 .

Study 1: Seasonal influences on blood parameters related with lipid metabolism were investigated in Pyrenean chamois. For this purpose, samples from a total of 67 animals were used. The Pyrenean chamois were captured in drive-nets during the FA $(n=32)$ and FD $(n=35)$ seasons. The FA season extended from June to October and the FD season extended from December to March. Chamois were captured with $10 \times 10-\mathrm{cm}$ mesh drive nets (Ziboni Ornitecnica, Bergamo, Italy). Capture and net locations were selected according to criteria and advice of collaborating gamekeepers. A line of beaters, composed of volunteers and gamekeepers, drove the animals toward the net. Once trapped in the net, they were immediately restrained and physically immobilized. Animals were restrained between $1-2 \mathrm{~h}$ for sampling and marking and then were released at the place of capture. The blood samples were collected from the jugular vein into tubes containing clot accelerator (TapVal, Aquisel, Selecta, Barcelona, Spain).

Study 2: We evaluated the differences between sampling from live or dead animals on biochemistry analytes in Pyrenean chamois. Serum samples from 32 animals of Study 1 captured during the FA season and from 31 dead animals obtained during controlled hunting were used. We collected samples from the heart of dead animals into tubes containing clot accelerator less than $2 \mathrm{~h}$ after the death of an animal. Only serum samples without hemolysis were used for the study. Age and body mass could not be determined in all cases due to the availability of only a partial carcass of some hunted animals.

Blood samples were placed into thermal boxes at $4 \mathrm{C}$ and taken to the laboratory in less than $5 \mathrm{~h}$ in all cases. The samples were centrifuged $(2,000 \times$ $\mathrm{G}$ ) for $5 \mathrm{~min}$ at room temperature, and supernatant was transferred into microcentrifuge tubes (Eppendorf, Hamburg, Germany), and stored at -80 C until analyses for no more than $2 \mathrm{yr}$.

\section{Laboratory analyses}

All chemical analytes in all samples were analyzed in one batch. Total cholesterol, HDL-C, LDL-C, triglycerides, ALP, and AST were measured with commercially available methods (Beckman Coulter Ireland Inc., County Clare, Ireland) according to manufacturer's instructions. The AChE activity was measured using acetylthiocholine as a substrate (Ceron et al. 1996). Bile acids were measured with a commercially available enzyme method (Total Bile Acid Assay, Diazyme Laboratories, Hannover, Germany). The NEFA and butyrate (D-3-hydroxibutyrate) analytes were measured with commercially available assays (Randox, Laboratories Ltd. Ardmore, Crumlin, UK). Albumin was determined using a commercially available assay (Albumin OSR 6102 Olympus Life and Material Science Europe GmbH, Lismeehan, County Clare, Ireland). Haptoglobin concentration was measured by a commercially available method (Tridelta Phase range haptoglobin kit, Tridelta Development, Brey, Ireland). 
TABle 1. Sex, age, and body mass of Pyrenean chamois (Rupicapra pyrenaica pyrenaica), hunted or captured between 2009 and 2012 in the Catalan Pyrenees of Spain, and included in a study of the effects of season and from sampling dead animals on serum biochemistries including biomarkers of inflammation and oxidative stress.

\begin{tabular}{|c|c|c|c|c|}
\hline \multirow[b]{2}{*}{ Season } & \multicolumn{2}{|c|}{ No. } & \multirow[b]{2}{*}{ Median age in years $\left(\mathrm{IQR}^{\mathrm{a}}\right)$} & \multirow[b]{2}{*}{ Median body mass in $\mathrm{kg}\left(\mathrm{IQR}^{\mathrm{a}}\right)$} \\
\hline & Alive or dead & Female/male & & \\
\hline \multirow[t]{2}{*}{ Food abundant } & Alive (32) & $15 / 17$ & $4.0(2.0-6.0)^{\mathrm{b}}$ & $24.5(21.5-28.0)$ \\
\hline & Dead (31) & $20 / 11$ & $9.5(7.0-13.0)^{\mathrm{c}}$ & $-^{\mathrm{d}}$ \\
\hline Food deficient & Alive (35) & $15 / 20$ & $4.0(3.0-5.5)$ & $23.0(20.0-25.5)$ \\
\hline
\end{tabular}

Total antioxidant capacity was measured using a colorimetric method developed by Erel (2004). The PON1 activity was determined using p-nitrophenyl acetate as a substrate following a previously described method (Tvarijonaviciute et al. 2012). All these analytes were measured in serum on an automated biochemistry analyzer (Olympus AU600 Automatic Chemistry Analyser, Olympus Europe GmbH, Hamburg, Germany). Cortisol and IGF-1 were analyzed with an automated solid-phase, enzyme-labeled chemiluminescent immunometric assay (Immulite System, Siemens Health Diagnostics, Deerfield, Illinois, USA). The assays were precise according to analytic validation guidelines (US Department of Health and Human Services 2001) as the intra- and interassay coefficients of variation were below $15 \%$.

\section{Statistical analysis}

Summarized data are shown as median and interquartile range (unless otherwise stated) that were calculated using routine descriptive statistical procedures and software (GraphPad Prism Version 5 for Windows, GraphPad Software, San Diego, California, USA). The D'Agostino-Pearson omnibus normality test was used to assess normality. A Student's $t$-test was used to compare changes in variables that were normally distributed (total cholesterol, HDL-C, PON1, TAC, IGF1, AST; ALP) and a Mann-Whitney $U$-test in those that were not normally distributed (LDL-C, Tg, albumin, AChE, Hp, bile acids, NEFA, cortisol, butyrate). Values of $P<0.05$ for two-sided analyses were considered significant.

\section{RESULTS}

\section{Study 1}

No statistically significant differences were observed in sex, age, or BW of the Pyrenean chamois included in our study between the FA and FD seasons (Table 1). Biochemistry data in Pyrenean chamois obtained in the FA and FD seasons are presented in Table 2. Significant increases in HDL-C (24\%; $P=0.001), \quad$ NEFA $(190 \% ; P=0.003)$, TAC $(68 \% ; P=0.049)$, and $\operatorname{Hp}(33 \% ; P=0.028)$ were observed in the FD season compared with the FA season. Albumin $(P=0.000)$ and IGF-1 $(P=0.008)$ showed statistically significant decreases of $10 \%$ and $11 \%$, respectively, in the FD season.

\section{Study 2}

No statistically significant differences were observed between the dead and alive animals of different sexes. The age data of the dead animals was available only in nine cases out of 31 , being higher in dead compared to live animals $(P=0.003)$. No data of body mass were available for dead animals (Table 1).

Biochemistry data in live and dead Pyrenean chamois (obtained in FA season) are presented in Table 3. Statistically significant higher concentrations were observed in serum LDL-C (22\%; $P=0.001), \quad \mathrm{Tg}(28 \%), \mathrm{AChE}$ $(50 \% ; P=0.000)$, NEFA $(383 \% ; P=0.000)$, albumin (18\%; $P=0.001), \quad$ IGF $-1(53 \%$; $P=0.007)$, cortisol $(959 \% ; P=0.000)$, and PON1 (20\%; $P=0.000)$ in samples collected from live animals in comparison to those collected from dead ones. The level of Hp was $60 \%$ higher in dead animals $(P=0.004)$. 
TABle 2. Biochemistry data related to season of Pyrenean chamois (Rupicapra pyrenaica pyrenaica) captured between 2009 and 2012 in the Catalan Pyrenees of Spain.

\begin{tabular}{|c|c|c|c|c|c|c|c|}
\hline Markers & Analyte $^{\mathrm{a}}$ & Units & Season $^{b}$ & Median & 25th Percentile & 75th Percentile & $P$ \\
\hline \multirow[t]{16}{*}{ Lipid metabolism } & \multirow[t]{2}{*}{ Tcol } & \multirow[t]{2}{*}{$\mathrm{mg} / \mathrm{dL}$} & FA & 83.50 & 64.65 & 97.73 & \multirow[t]{2}{*}{0.323} \\
\hline & & & FD & 94.60 & 66.50 & 107.30 & \\
\hline & \multirow[t]{2}{*}{ HDL-C } & \multirow[t]{2}{*}{$\mathrm{mg} / \mathrm{dL}$} & FA & 46.25 & 36.40 & 55.10 & \multirow[t]{2}{*}{0.001} \\
\hline & & & FD & 57.50 & 43.60 & 66.00 & \\
\hline & \multirow[t]{2}{*}{ LDL-C } & \multirow[t]{2}{*}{$\mathrm{mg} / \mathrm{dL}$} & FA & 32.05 & 26.80 & 41.05 & \multirow[t]{2}{*}{0.479} \\
\hline & & & FD & 33.80 & 23.20 & 41.40 & \\
\hline & \multirow[t]{2}{*}{$\mathrm{Tg}$} & \multirow[t]{2}{*}{$\mathrm{mg} / \mathrm{dL}$} & FA & 63.87 & 51.62 & 123.20 & \multirow[t]{2}{*}{0.535} \\
\hline & & & FD & 76.51 & 45.13 & 96.59 & \\
\hline & \multirow[t]{2}{*}{ AChE } & \multirow[t]{2}{*}{ IU/L } & FA & 0.60 & 0.50 & 0.70 & \multirow[t]{2}{*}{0.860} \\
\hline & & & FD & 0.60 & 0.50 & 0.70 & \\
\hline & \multirow[t]{2}{*}{ Bilac } & \multirow[t]{2}{*}{$\mu \mathrm{mol} / \mathrm{L}$} & FA & 5.94 & 3.36 & 19.60 & \multirow[t]{2}{*}{0.267} \\
\hline & & & FD & 4.54 & 2.13 & 10.69 & \\
\hline & \multirow[t]{2}{*}{ NEFA } & \multirow[t]{2}{*}{$\mathrm{mEq} / \mathrm{L}$} & FA & 0.29 & 0.17 & 0.72 & \multirow[t]{2}{*}{0.003} \\
\hline & & & FD & 0.84 & 0.34 & 1.22 & \\
\hline & \multirow[t]{2}{*}{ Butyrate } & \multirow[t]{2}{*}{$\mathrm{mg} / \mathrm{dL}$} & FA & 0.30 & 0.25 & 0.35 & \multirow[t]{2}{*}{0.061} \\
\hline & & & FD & 0.33 & 0.25 & 0.48 & \\
\hline \multirow[t]{4}{*}{ Nutrition } & \multirow[t]{2}{*}{ Albumin } & \multirow[t]{2}{*}{$\mathrm{g} / \mathrm{dL}$} & FA & 3.14 & 2.83 & 3.36 & \multirow[t]{2}{*}{0.000} \\
\hline & & & FD & 2.84 & 2.59 & 2.94 & \\
\hline & IGF-1 & $\mathrm{ng} / \mathrm{mL}$ & FA & 147.00 & 120.60 & 182.40 & 0.008 \\
\hline & & & FD & 130.80 & 109.20 & 147.30 & \\
\hline Stress & Cortisol & $\mathrm{nmol} / \mathrm{L}$ & FA & 11.65 & 4.39 & 16.73 & 0.249 \\
\hline & & & FD & 12.90 & 7.58 & 16.60 & \\
\hline Acute phase proteins & Нp & $\mathrm{g} / \mathrm{L}$ & FA & 0.03 & 0.02 & 0.04 & 0.028 \\
\hline & & & FD & 0.04 & 0.03 & 0.05 & \\
\hline Liver enzymes & ALP & $\mathrm{IU} / \mathrm{L}$ & FA & 434.10 & 284.10 & 677.10 & 0.764 \\
\hline & & & FD & 466.40 & 333.60 & 643.20 & \\
\hline & AST & IU/L & FA & 217.10 & 142.00 & 338.50 & 0.764 \\
\hline & & & FD & 233.20 & 166.80 & 321.60 & \\
\hline Antioxidants & TAC & $\mathrm{mmol} / \mathrm{L}$ & FA & 0.19 & 0.05 & 0.33 & 0.049 \\
\hline & & & FD & 0.32 & 0.20 & 0.36 & \\
\hline & PON1 & $\mathrm{IU} / \mathrm{mL}$ & FA & 15.38 & 13.39 & 17.64 & 0.825 \\
\hline & & & FD & 15.45 & 13.51 & 17.26 & \\
\hline
\end{tabular}

${ }^{a}$ Tcol = total cholesterol; HDL-C = high-density lipoprotein cholesterol; LDL-C = low-density lipoprotein cholesterol; Tg=triglycerides; $\mathrm{AChE}=$ acetylcholinesterase; Bilac $=$ bile acids; NEFA = nonesterified fatty acid; IGF-1 = insulin-like growth factor I; Hp = haptoglobin; ALP = alkaline phosphatase; AST = aspartate aminotransferase; TAC $=$ total antioxidant capacity; PON1 = paraoxonase- 1 .

${ }^{\mathrm{b}} \mathrm{FA}=$ food abundant season; $\mathrm{FD}=$ food deficient season.

\section{DISCUSSION}

\section{Seasonality}

In Pyrenean chamois in the FD season, we observed that lipid mobilization produced statistically significant increases in HDL-C and NEFA and a tendency for increases in total cholesterol, LDL-C, and triglycerides. This could be due to the lack of pasture and the low nutrition value of the existing feed available during the FD season, which leads to poor nutrition of the wild animals, characterized by a negative energy balance when endogenous fat becomes the main source of energy (Wolkers et al. 1994). Furthermore, lipid mobilization was accompanied by increases in plasma concentrations of butyrate and $\mathrm{Hp}$ in the animals during the FD season. These increases could be explained by the fat mobilization resulting in elevated concentrations of blood ketone bodies in most mammals (Wolkers et al. 1994). However, in the present 
Table 3. Biochemistry data of Pyrenean chamois (Rupicapra pyrenaica pyrenaica) hunted or captured alive from 2009 to 2012 in the Catalan Pyrenees of Spain for the study of the effects of postmortem sampling on blood analytes.

\begin{tabular}{|c|c|c|c|c|c|c|c|}
\hline Markers & Analyte $^{\mathrm{a}}$ & Units & Animal status & Median & 25th Percentile & 75th Percentile & $P$ \\
\hline \multirow[t]{16}{*}{ Lipid metabolism } & \multirow[t]{2}{*}{ Tcol } & \multirow[t]{2}{*}{$\mathrm{mg} / \mathrm{dL}$} & Alive & 83.50 & 64.65 & 97.73 & \multirow[t]{2}{*}{0.178} \\
\hline & & & Dead & 81.70 & 56.00 & 91.70 & \\
\hline & \multirow[t]{2}{*}{ HDL-C } & \multirow[t]{2}{*}{$\mathrm{mg} / \mathrm{dL}$} & Alive & 46.25 & 36.40 & 55.10 & \multirow[t]{2}{*}{0.444} \\
\hline & & & Dead & 47.40 & 31.10 & 52.00 & \\
\hline & \multirow[t]{2}{*}{ LDL-C } & \multirow[t]{2}{*}{$\mathrm{mg} / \mathrm{dL}$} & Alive & 32.05 & 26.80 & 41.05 & \multirow[t]{2}{*}{0.001} \\
\hline & & & Dead & 26.30 & 17.70 & 29.20 & \\
\hline & \multirow[t]{2}{*}{$\mathrm{Tg}$} & \multirow[t]{2}{*}{$\mathrm{mg} / \mathrm{dL}$} & Alive & 63.87 & 51.62 & 123.20 & \multirow[t]{2}{*}{0.028} \\
\hline & & & Dead & 49.77 & 19.85 & 101.90 & \\
\hline & \multirow[t]{2}{*}{ AChE } & \multirow[t]{2}{*}{$\mathrm{IU} / \mathrm{L}$} & Alive & 0.60 & 0.50 & 0.70 & \multirow[t]{2}{*}{0.000} \\
\hline & & & Dead & 0.40 & 0.30 & 0.50 & \\
\hline & \multirow[t]{2}{*}{ Bilac } & \multirow[t]{2}{*}{$\mu \mathrm{mol} / \mathrm{L}$} & Alive & 5.94 & 3.36 & 19.60 & \multirow[t]{2}{*}{0.081} \\
\hline & & & Dead & 16.14 & 5.63 & 26.29 & \\
\hline & \multirow[t]{2}{*}{ NEFA } & \multirow[t]{2}{*}{$\mathrm{mEq} / \mathrm{L}$} & Alive & 0.29 & 0.17 & 0.72 & \multirow[t]{2}{*}{0.000} \\
\hline & & & Dead & 0.06 & 0.03 & 0.11 & \\
\hline & \multirow[t]{2}{*}{ Butyrate } & \multirow[t]{2}{*}{$\mathrm{mg} / \mathrm{dL}$} & Alive & 0.30 & 0.25 & 0.35 & \multirow[t]{2}{*}{0.550} \\
\hline & & & Dead & 0.30 & 0.22 & 0.40 & \\
\hline \multirow[t]{4}{*}{ Nutrition } & \multirow[t]{2}{*}{ Albumin } & \multirow[t]{2}{*}{$\mathrm{g} / \mathrm{dL}$} & Alive & 3.14 & 2.83 & 3.36 & \multirow[t]{2}{*}{0.001} \\
\hline & & & Dead & 2.67 & 2.28 & 3.09 & \\
\hline & IGF-1 & $\mathrm{ng} / \mathrm{mL}$ & Alive & 147.00 & 120.60 & 182.40 & 0.007 \\
\hline & & & Dead & 95.80 & 58.10 & 161.80 & \\
\hline Stress & Cortisol & $\mathrm{nmol} / \mathrm{L}$ & Alive & 11.65 & 4.39 & 16.73 & 0.0001 \\
\hline & & & Dead & 1.10 & 0.60 & 3.60 & \\
\hline Acute phase proteins & Нp & $\mathrm{g} / \mathrm{L}$ & Alive & 0.03 & 0.02 & 0.04 & 0.004 \\
\hline & & & Dead & 0.05 & 0.03 & 0.06 & \\
\hline Liver enzymes & ALP & $\mathrm{IU} / \mathrm{L}$ & Alive & 434.10 & 284.10 & 677.10 & 0.741 \\
\hline & & & Dead & 480.20 & 329.00 & 746.40 & \\
\hline & AST & IU/L & Alive & 217.10 & 142.00 & 338.50 & 0.741 \\
\hline & & & Dead & 240.10 & 164.50 & 373.20 & \\
\hline Antioxidants & TAC & $\mathrm{mmol} / \mathrm{L}$ & Alive & 0.19 & 0.05 & 0.33 & 0.864 \\
\hline & & & Dead & 0.20 & 0.00 & 0.40 & \\
\hline & PON1 & $\mathrm{IU} / \mathrm{mL}$ & Alive & 15.38 & 13.39 & 17.64 & 0.000 \\
\hline & & & Dead & 12.83 & 7.88 & 14.75 & \\
\hline
\end{tabular}

${ }^{\text {a }}$ Tcol = total cholesterol; HDL-C = high-density lipoprotein cholesterol; LDL-C = low-density lipoprotein cholesterol; $\mathrm{Tg}=$ triglycerides; $\mathrm{AChE}=$ acetylcholinesterase; Bilac $=$ bile acids; NEFA = nonesterified fatty acid; IGF-1 = insulin-like growth factor I; Hp = haptoglobin; $\mathrm{ALP}=$ alkaline phosphatase; AST $=$ aspartate aminotransferase; $\mathrm{TAC}=$ total antioxidant capacity; $\mathrm{PON} 1=$ paraoxonase-1.

study, the increases of butyrate and Hp were of low magnitude, and their values were within the normal ranges described for goats (González et al. 2011). Taken all together, these data suggested that Pyrenean chamois presented lipid mobilization that does not produce an overt ketoacidosis although acetate, acetoacetate, or both should have been ideally measured in order to totally dismiss the presence of ketoacidosis in these animals. However, in line with our data, Wolker et al.
(1994) indicated that to prevent ketosis, wild ungulates may obtain glucogenetic precursors from body protein, resulting in a decreased protein content of body tissues that could be reflected in the lower albumin that presented in our animals in the FD season.

No significant changes were observed in PON1 levels in animals captured in the FA or FD seasons while a significant increase of almost twofold was observed in TAC in the FD season. Similarly, in cows during the first 
2 wk of lactation, characterized by lipid mobilization, an increase in total antioxidant status is reported (Castillo et al. 2006). Increased TAC could be attributed to an increased endogenous antioxidant protection to counteract free radicals (Dimri et al. 2008).

The observed lower circulating concentrations of IGF-1 in animals in the FD season could be attributed to the poor nutrition of the animals during this season. Insulin-like growth factor-1, which is synthesized in the liver, is a small polypeptide hormone consisting of 70 amino acids. It is involved in the regulation of growth and metabolism and mediates many of the anabolic effects of growth hormone in different tissues such as bones, muscles, kidneys, spleen, hearth, liver, or mammary gland (Le Roith et al. 2001). In humans, circulating IGF-1 levels were associated with nutritional status and glycemic control (Juul 2003). Furthermore, reports in humans and different species of animals such as rats and pigs show that IGF-1 levels decrease during feed restriction (Prewitt et al. 1982; Spicer et al. 1992; Juul 2003).

\section{Postmortem changes}

Lower LDL-C and triglycerides were observed in samples collected from dead compared to live animals. In human medicine, to determine cholesterol and triglycerides including lipoprotein, electrophoresis can be performed with blood samples obtained within $48 \mathrm{~h}$ after death (Forrest 1993). Therefore, our observation of decreased lipid concentrations together with decreased albumin, IGF-1, and NEFA could suggest lower lipid metabolism in the animals that died or it could be due to postmortem degradation of these analytes. Future studies evaluating this last possibility would be required in order to clarify this topic. On the other hand, 10-fold higher serum cortisol concentrations were observed in samples from live animals compared to samples from dead animals. These results accord with previous studies that indicate that capture and manipulation of wild animals is a highly stressful situation for them (Ladewig 1994; Morton et al. 1995; De
Villiers et al. 1997). Along this line, some or all of our observed differences in blood parameters between live and dead animals could be attributed to the acute stress suffered by an animal that had been captured alive. For instance, mobilization of lipids was also associated with increases in glucocorticoid levels, which could explain the observed higher levels of serum LDL-C and triglycerides in live animals. Furthermore, higher PON1 activity in live Pyrenean chamois could be also explained by the presence of increased endogenous glucocorticoids in those animals due to stress, as a relationship between PON1 and increased glucocorticoids is described in other species (Bin Ali et al. 2003; Tvarijonaviciute et al. 2015).

We postulate that determination of enzyme activity in postmortem samples is not very useful in practice, as intracellular enzymes are rapidly released into blood during autolysis (Forrest 1993). Thus, the observed lower serum AChE activity in dead animals could possibly be explained by sample degradation before it could be processed and conserved at low temperature. The differences in $\mathrm{Hp}$ concentrations, although being statistically significant, were of very low magnitude $(0.02$ $\mathrm{g} / \mathrm{L})$ and within the range for healthy animals. We postulate that the Hp changes in dead animals would have no effect on the interpretation of this analyte. Overall, the second part of the study had the limitation of not having used the same animals alive and dead for comparison of circulating concentrations of analytes. However, this was not possible due to ethical reasons.

The values of evaluated analytes that we report should not be used as reference intervals for individual animals because of the relatively low number of animals we included. However, the results of our study demonstrate that season should be taken in account when evaluating serum biochemistry in Pyrenean chamois because in the FD season these animals presented lipid mobilization, decreased albumin and IGF-1, and increased total antioxidant capacity compared with the FA season. In addition, if samples are taken from dead animals, decreases in serum 
LDL-C, triglycerides, albumin, PON1, AChE, NEFA, cortisol, IGF-1, and an increase in Hp could be expected.

\section{ACKNOWLEDGMENTS}

Additional financial support was provided by the Program "Juan de la Cierva" of Ministerio de Economia y Competitividad, Spain through a postdoctoral grant.

\section{LITERATURE CITED}

Bateson P, Bradshaw EL. 1997. Physiological effects of hunting red deer (Cervus elaphus). Proc Biol Sci 264: 1707-1714.

Bin Ali A, Zhang Q, Lim YK, Fang D, Retnam L, Lim SK. 2003. Expression of major HDL-associated antioxidant PON-1 is gender dependent and regulated during inflammation. Free Radicals Biol Med 34:824829.

Castillo C, Hernández J, Valverde I, Pereira V, Sotillo J, Alonso ML, Benedito JL. 2006. Plasma malonaldehyde (MDA) and total antioxidant status (TAS) during lactation in dairy cows. Res Vet Sci 80:133139.

Ceron JJ, Fernandex del Palacio MJ, Bernal LJ, Gutierrez C. 1996. Automated spectrophotometric method using 2,2'-dithiodipyridine acid for determination of cholinesterase in whole blood. J AOAC Int 79:757763.

Crampe JP, Gaillard JM, Loison A. 2002. L'enneigement hivernal: Un facteur de variation du recrutement chez l'isard (Rupicapra pyrenaica pyrenaica). Can J Zool 80:1306-1312. [French.]

De Villiers MS, van Jaarsveld AS, Meltzer DGA, Richardson PRK. 1997. Social dynamics and the cortisol response to immobilization stress of the African wild dog, Lycaon pictus. Horm Behav 31:3-14.

Dimri U, Ranjan R, Kumar N, Sharma MC, Swarup D, Sharma B, Kataria M. 2008. Changes in oxidative stress indices, zinc and copper concentrations in blood in canine demodicosis. Vet Parasitol 154:98102 .

Erel O. 2004. A novel automated direct measurement method for total antioxidant capacity using a new generation, more stable ABTS radical cation. Clin Biochem 37:277-285.

Forrest ARW. 1993. ACP Broadsheet no. 137: April 1993. Obtaining samples at post mortem examination for toxicological and biochemical analyses. J Clin Pathol 46:292-296.

Gibert P. 1991. Conséquences de la capture et des manipulations sur la physiologie des ongulés sauvages. Incidence pathologique. Bilan et connaissances. Bull Mens Off Nat Chasse 161:31-40. [French.]

González FH, Hernández F, Madrid J, Martínez-Subiela S, Tvarijonaviciute A, Cerón JJ, Tecles F. 2011. Acute phase proteins in experimentally induced pregnancy toxemia in goats. J Vet Diagn Invest 23:57-62.

Gonzalez G, Crampe JP. 2001. Mortality patterns in a protected population of isards (Rupicapra pyrenaica). Can J Zool 79:2072-2079.

Juul A. 2003. Serum levels of insulin-like growth factor I and its binding proteins in health and disease. Growth Horm IGF Res 13:113-170.

Ladewig J. 1994. Stress. In: Veterinarmedizinische Endokrinologie, Dokke F, editor. Fischer, Stuttgart, Germany, pp. 379-398. [German.]

Le Roith D, Bondy C, Yakar S, Liu JL, Butler A. 2001. The somatomedin hypothesis. Endocr Rev 22:53-74.

Morton DJ, Anderson E, Foggin CM, Kock MD, Tiran EP. 1995. Plasma cortisol as an indicator of stress due to capture and translocation in wildlife species. Vet Rec 136:60-63.

Pérez-Barberia FJ, Mutuberria G, Nores C. 1998. Reproductive parameters, kidney fat index, and grazing activity relationships between the sexes in Cantabrian chamois Rupicapra pyrenaica parva. Acta Theriol 43:311-324.

Prewitt TE, D’Ercole AJ, Switzer BR, Van Wyk JJ. 1982. Relationship of serum immunoreactive somatomedin-C to dietary protein and energy in growing rats. $J$ Nutr 112:144-150.

Spicer LJ, Crowe MA, Prendiville DJ, Goulding D, Enright WJ. 1992. Systemic but not intraovarian concentrations of insulin-like growth factor-I are affected by short-term fasting. Biol Reprod 46:920 925 .

Tvarijonaviciute A, Caldin M, Martinez-Subiela S, Tecles F, Pastor J, Ceron JJ. 2015. Serum paraoxonase 1 and butyrylcholinesterase in dogs with hyperadrenocorticism. Vet J 203:262-263.

Tvarijonaviciute A, Tecles F, Caldin M, Tasca S, Cerón J. 2012. Validation of spectrophotometric assays for serum paraoxonase type-1 measurement in dogs. Am $J$ Vet Res 73:34-41.

US Department of Health and Human Services. 2001. Guidance for industry: Bioanalytical method validation. US Department of Health and Human Services, Food and Drug Administration, Center for Drug Evaluation and Research, Center for Veterinary Medicine. www.fda.gov/downloads/ Drugs/GuidanceComplianceRegulatoryInformation/ Guidances/UCM070107.pdf. Accessed February 2017.

Weber E. 2004. El rebeco norteño y meridional. Ediciones Omega, Barcelona, Spain, 196 pp. [Spanish.]

Wolkers H, Wensing T, Schonewille TT. 1994. Effect of undernutrition on haematological and serum biochemical characteristics in red deer (Cervus elaphus). Can J Zool 72:1291-1296.

Submitted for publication 23 May 2016. Accepted 17 January 2017. 